\title{
Physico-Chemical Characteristics of Cookies Prepared with Tomato Pomace Powder
}

\author{
Mudasir Ahmad Bhat* and Hafiza Ahsan
}

Department of Post-Harvest Technology, SKUAST-K, Shalimar, Srinagar

\begin{abstract}
This study was conducted to investigate the physico-chemical characteristics of cookies added with different levels of tomato pomace powder. Cookies were prepared with six different levels of tomato pomace powder $(0,5,10,15,20$ and $25 \%)$ and the physicochemical properties were examined. Crude protein and ash content of cookies containing $20,25 \%$ of tomato pomace powders were significantly higher than those of control and rest of treatments $(p<0.05)$. The spread factor of control cookie was higher than that of cookies containing $5,10,15,20$ and $25 \%$ of tomato pomace powder. The incorporation of tomato pomace powder in cookie lowered the lightness values but increased redness and yellowness values. Sensory evaluation revealed that overall desirability scores were not significantly different between control and tomato pomace powder incorporated cookies. The cookies up to $5 \%$ substitution of powder were found acceptable by the consumers.
\end{abstract}

Keywords: Tomato pomace powder; Cookies; Physico-chemical characteristics

\section{Introduction}

Today foods are not only intended to satisfy hunger and to provide necessary nutrients for humans but also to prevent nutrition-related diseases and improve physical and mental well-being [1]. Functional foods are quiet remedy. Cookies are widely consumed baked products which can be served from breakfast to bedtime. Cookies are appreciated for their taste, aroma, convenience, and long shelf stability due to low moisture content. Recently, increasing consumer demand for healthier foods has triggered the development of cookies made with natural ingredients exhibiting functional properties and providing specific health benefits beyond those to be gained from traditional nutrients. Tomatoes are an integral part of the human diet rich in several nutrients including vitamin $\mathrm{A}$, vitamin $\mathrm{C}$, potassium, calcium and lycopene. Most tomatoes produced worldwide are used as tomato juice, paste, ketchup and sauce, although a number of tomatoes are commonly consumed fresh [2]. Recent studies have indicated that a diet rich in tomatoes and tomato products is associated with a reduced risk of certain cancers [3]. The consensus seems to be that lycopene; a major carotenoid present in red tomatoes having antioxidant capacity is a natural cancer-fighting agent. It is also suggested that complex interactions among multiple nutrients present in tomatoes contribute to its anticancer properties [4].

Tomato pomace is highly perishable in its fresh state because it contains about $95 \%$ moisture and its storage is difficult [5]. Therefore, the waste is just dumped and allowed to decay which increases landfill costs and societal concerns about solid waste. These generated interest in finding an economical outlet for this byproduct. Bakery product cookies are fast and convenient food based on wheat. Cookies, which constitute an important item of bakery industry have now become a common item of consumption among all classes of people with tea or coffee, Different variety of cookies are used as one of the tasty and nutritious snacks. Cookies are more popular as a convenient food.

In present scenario, there is an increasing demand for conversion of fruit and vegetable wastes into useful products as well as to minimize environmental impact of these by-products. Successful incorporation of tomato pomace into bakery products that deliver physiologically active components represents a major opportunity for food processors providing the consumer a healthy wheat based product to choose from which is currently lacking in the marketplace. Keeping in view the bioactive potential and health benefits of tomato pomace, the proposed study shall be undertaken to investigate the utilization of tomato pomace for development of wheat based cookies with the objective to evaluate the effects of tomato powder on the quality characteristics of cookies. Cookies were prepared with tomato powder which was substituted for $0 \%, 5 \%, 10 \%, 15 \%, 20 \%$ and $25 \%$ of wheat flour and the physicochemical and sensory properties were investigated.

\section{Materials and Methods}

\section{Materials}

Ingredients for cookies such as wheat flour, milk, sugar, butter, egg white and baking powder were purchased from a local market. Tomato pomace prepared from local tomato variety was dried in a cabinet dryer at $60^{\circ} \mathrm{C}$ and then grinded in a grinder-mixer to obtain tomato pomace powder with following proximate composition: moisture $14.89 \%$, protein $20.36 \%$, fat $0.35 \%$, and ash $8.97 \%$.

\section{Preparation of cookies}

The cookie recipe used in this study is shown in Table 1 . Tomato pomace powder was used to replace part of the whole wheat flour $(0 \%$, $5 \%, 10 \%, 15 \%, 20 \%$ and $25 \%)$ in a standard cookie recipe. Egg white, butter and sugar were creamed in a hand mixer for $3 \mathrm{~min}$. Flour, tomato pomace powder and baking powder were sifted and added to the liquid ingredients and mixed for 30 seconds. The firm dough was then sheeted to a thickness of $5 \mathrm{~mm}$ thick with roller and cut with a cookie cutter of

*Corresponding author: Mudasir Ahmad Bhat, Department of Post-Harvest Technology, SKUAST-K, Shalimar, Srinagar, Tel: 01932-24529; E-mail: mudasagar@gmail.com

Received November 16, 2015; Accepted December 11, 2015; Published December 23, 2015

Citation: Bhat MA, Ahsan H (2015) Physico-Chemical Characteristics of Cookies Prepared with Tomato Pomace Powder. J Food Process Technol 7: 543. doi:10.4172/2157-7110.1000543

Copyright: $\odot 2015$ Bhat MA, et al. This is an open-access article distributed unde the terms of the Creative Commons Attribution License, which permits unrestricted use, distribution, and reproduction in any medium, provided the original author and source are credited. 
$50 \mathrm{~mm}$ diameter. The cookies were then transferred to a lightly greased baking tray and baked in an oven at an upper heating temperature of $160^{\circ} \mathrm{C}$ for $15 \mathrm{~min}$. The baked cookies were removed from the baking pan, cooled to room temperature for $1 \mathrm{hr}$ before analysis.

\section{Proximate composition analysis}

Moisture, crude protein, crude fat and ash content were determined according to the AOAC method [6].

\section{Physical characteristics}

Cookie diameter (D) and thickness (T) of six cookies were measured as described in the AACC methods [7]. The spread factor was calculated as $\mathrm{D} / \mathrm{T}$. The volume of cookies were determined by seed displacement method

\section{Color measurement}

Surface color of cookies was determined by measuring tristimulus L (lightness), a (redness), b (yellowness) values with a colorimeter calibrated with a white standard plate $(\mathrm{L}=+98.5, \mathrm{a}=+0.07, \mathrm{~b}=-0.40)$.

\section{Sensory evaluation}

Sensory evaluation was conducted after cooling the cookies for $1 \mathrm{hr}$ at room temperature. Cookies were placed on a plastic dish coded by a three-digit random number and offered to 8 trained panelists in an individual booth with lighting. Surface color, taste, texture, appearance and overall acceptability were evaluated using the five-point scale with 5 indicating strong attributes.

\section{Statistical analysis}

All data were recorded as means \pm standard deviation of at least triplicate measurements. Means were compared with Duncan's multiple range tests with $\alpha=0.05$ using SAS (Statistical Analysis System, version 8.12).

\section{Results and Discussion}

\section{Proximate composition}

The results of the proximate composition of cookies prepared with tomato powder are shown in Table 2. Moisture content of control was $2.49 \%$ and that of cookies containing tomato powder ranged from 2.24 to $3.39 \%$. Crude protein and ash content values of the cookies containing tomato powder of 5.0, 7.5 and $10.0 \%$ were significantly higher than those of control and $2.5 \%$ added sample $(\mathrm{p}<0.05)$. This is attributable to the higher protein and ash content of tomato powder than wheat flour. Crude fat contents were $21.71-21.85 \%$ and no significant differences among cookies were observed.

\section{Physical characteristics}

Cookie diameter, thickness and spread factor are shown in Table 3. There were no significant differences in the diameter and thickness of the cookies between those containing up to $5.0 \%$ and the control. However, significant differences were found with higher percentages of tomato powder $(\mathrm{p}<0.05)$. Larger diameter and lower thickness values were observed in the formulations containing 7.5 and $10.0 \%$ of tomato powder. Thus, it could be stated that the incorporation of tomato powder in the cookies at the level of 7.5 and $10.0 \%$ affected cookie expansion by lowering gas retaining power below that of wheat flour [8]. The spread factor of cookies made with 5.0, 7.5 and $10.0 \%$ tomato powder was significantly higher than that of control $(\mathrm{p}<0.05)$, but a trend with the varying levels of tomato powder substitution for flour was not found. Chung and Kwon [8] reported that cookies made with yam powder exhibited a reduction in size and thickness as the content of yam powder increased. According to Kim et al. [9] barley germ increased cookie diameter and spread ratio, whereas decreased thickness and weight as the barley germ substitution level increased, and they have proposed that such increases in diameter and spread ratio may be due to the decrease in cookie dough consistency with increasing level of barley germ in the cookie formula. Dissimilar results have been

\begin{tabular}{|c|c|c|c|c|c|c|}
\hline \multirow[t]{2}{*}{ Ingredients \% } & \multicolumn{5}{|c|}{ Treatment combinations } & \multirow[b]{2}{*}{ D1T6 } \\
\hline & D1T1 & D1T2 & D1T3 & D1T4 & D1T5 & \\
\hline Flour (g) & 200 & 190 & 180 & 170 & 160 & 150 \\
\hline Tomato pomace powder (\%) & 0 & 5 & 10 & 15 & 20 & 25 \\
\hline Butter (g) & 50 & 50 & 50 & 50 & 50 & 50 \\
\hline Milk powder (g) & 50 & 50 & 50 & 50 & 50 & 50 \\
\hline Sugar (g) & 100 & 100 & 100 & 100 & 100 & 100 \\
\hline Baking powder (g) & 2 & 2 & 2 & 2 & 2 & 2 \\
\hline Egg white (No.s) & 1 & 1 & 1 & 1 & 1 & 1 \\
\hline
\end{tabular}

Table 1: Cookie recipe combinations used in the study.

\begin{tabular}{|c|c|c|c|c|}
\hline & Moisture (\%) & Crude protein (\%) & Ash (\%) & Crude fat (\%) \\
\hline Wheat flour & $14.45 \pm 0.19$ & $9.50 \pm 0.83$ & $0.48 \pm 0.01$ & $0.87 \pm 0.01$ \\
\hline Tomato pomace powder & $10.20 \pm 0.75$ & $18.25 \pm 0.25$ & $7.25 \pm 0.05$ & $0.65 \pm 0.09$ \\
\hline D1T1 & $2.49 \pm 0.10^{\mathrm{a}}$ & $5.186 \pm 0.25^{a}$ & $4.883 \pm 0.61^{\mathrm{a}}$ & $21.71 \pm 0.01^{a}$ \\
\hline D1T2 & $2.40 \pm 0.20^{\mathrm{a}}$ & $5.503 \pm 0.20^{b}$ & $4.844 \pm 0.22^{a}$ & $21.80 \pm 0.02^{b}$ \\
\hline D1T3 & $3.39 \pm 0.10^{b}$ & $6.25 \pm 0.22^{c}$ & $4.916 \pm 0.10^{b}$ & $21.81 \pm 0.55^{b}$ \\
\hline D1T4 & $2.24 \pm 0.01^{c}$ & $6.406 \pm 0.01^{d}$ & $4.920 \pm 0.01^{b}$ & $21.82 \pm 0.61^{b}$ \\
\hline D1T5 & $2.97 \pm 0.01^{d}$ & $6.446 \pm 0.01^{d}$ & $4.912 \pm 0.01^{b}$ & $21.83 \pm 0.10^{b}$ \\
\hline D1T6 & $3.24 \pm 0.02^{\mathrm{ab}}$ & $6.870 \pm 0.01^{\mathrm{ab}}$ & $4.927 \pm 0.02^{b}$ & $21.85 \pm 0.01^{c}$ \\
\hline
\end{tabular}

Each value is mean \pm standard deviation (SD).

Means with different letters within a column are significantly different from each other at $\alpha=0.05$ as determined by Duncan's multiple range tests.

Table 2: Proximate compositions of cookies prepared with tomato powder. 


\begin{tabular}{|c|c|c|c|c|c|c|}
\hline Groups & D1T1 & D1T2 & D1T3 & D1T4 & D1T5 & D1T6 \\
\hline Diameter(cm) & $19.26 \pm 0.10^{a}$ & $19.30 \pm 0.10^{b}$ & $19.33 \pm 0.05^{c}$ & $19.75 \pm 0.02^{d}$ & $19.92 \pm 0.25^{\mathrm{ab}}$ & $19.96 \pm 0.10^{\mathrm{ac}}$ \\
\hline Thickness (cm) & $3.10 \pm 0.10^{\mathrm{a}}$ & $2.85 \pm 0.08^{b}$ & $2.82 \pm 0.12^{c}$ & $2.75 \pm 0.25^{d}$ & $2.64 \pm 0.54^{\mathrm{ab}}$ & $2.55 \pm 0.09^{a c}$ \\
\hline Spread factor & $6.21 \pm 0.06^{a}$ & $6.77 \pm 0.12^{\mathrm{b}}$ & $6.85 \pm 0.25^{c}$ & $7.18 \pm 0.12^{d}$ & $7.54 \pm 0.25^{\mathrm{ab}}$ & $7.82 \pm 0.01^{\mathrm{ac}}$ \\
\hline
\end{tabular}

Each value is mean $\pm \mathrm{SD}$.

Means with different letters within a row are significantly different from each other at $\alpha=0.05$ as determined by Duncan's multiple range test.

Table 3: Diameter, thickness and spread factor of cookies prepared with tomato powder.

\begin{tabular}{|c|c|c|c|}
\hline Group & $\mathbf{L}$ & $\mathbf{a}$ & b \\
\hline D1T1 & $52.33 \pm 0.88^{a}$ & $3.31 \pm 0.16^{a}$ & $30.47 \pm 1.16^{a}$ \\
\hline D1T2 & $50.35 \pm 0.22^{b}$ & $5.68 \pm 0.01^{b}$ & $37.63 \pm 0.10^{b}$ \\
\hline D1T3 & $48.22 \pm 0.30^{\circ}$ & $6.74 \pm 0.25^{c}$ & $36.66 \pm 2.45^{c}$ \\
\hline D1T4 & $48.20 \pm 2.88^{c}$ & $7.49 \pm 0.29^{d}$ & $37.85 \pm 0.36^{b}$ \\
\hline D1T5 & $47.55 \pm 0.55^{d}$ & $8.33 \pm 0.90^{\mathrm{ab}}$ & $41.59 \pm 0.12^{d}$ \\
\hline D1T6 & $47.45 \pm 0.10^{d}$ & $8.56 \pm 0.01^{\mathrm{ab}}$ & $41.66 \pm 0.01^{d}$ \\
\hline
\end{tabular}

Each value is mean \pm SD.

Means with different letters within a column are significantly different from each other at $\alpha=0.05$ as determined by Duncan's multiple range tests.

Table 4: Colorimetric characteristics of cookies prepared with tomato powder.

\begin{tabular}{|c|c|c|c|c|}
\hline Group & Taste & Texture & Color & Appearance \\
\hline D1T1 & $4.22 \pm 0.85^{\mathrm{a}}$ & $3.55 \pm 0.80^{\mathrm{a}}$ & $3.44 \pm 0.10^{\mathrm{a}}$ & $3.62 \pm 0.01^{\mathrm{a}}$ \\
\hline D1T2 & $4.25 \pm 0.02^{\mathrm{a}}$ & $3.85 \pm 0.25^{\mathrm{b}}$ & $4.56 \pm 1.41^{\mathrm{b}}$ & $4.50 \pm 1.60^{\mathrm{b}}$ \\
\hline D1T3 & $3.24 \pm 1.21^{\mathrm{b}}$ & $3.65 \pm 0.68^{\mathrm{b}}$ & $3.28 \pm 0.98^{\mathrm{a}}$ & $3.68 \pm 0.27^{\mathrm{a}}$ \\
\hline D1T4 & $3.29 \pm 0.58^{\mathrm{b}}$ & $3.22 \pm 0.01^{\mathrm{a}}$ & $3.3 \pm 0.10^{\mathrm{a}}$ & $3.25 \pm 0.01^{\mathrm{a}}$ \\
\hline D1T5 & $3.88 \pm 0.25^{\mathrm{c}}$ & $3.26 \pm 0.05^{\mathrm{a}}$ & $3.35 \pm 0.02^{\mathrm{a}}$ & $3.24^{\mathrm{b}}$ \\
\hline D1T6 & $3.10 \pm 1.25^{\mathrm{b}}$ & $3.45 \pm 2.15^{\mathrm{a}}$ & $2.25 \pm 0.05^{\mathrm{c}}$ & $2.12^{\mathrm{a}}$ \\
\hline
\end{tabular}

Each value is mean \pm SD.

Means with different letters within a column are significantly different from each other at $\alpha=0.05$ as determined by Duncan's multiple range tests.

Table 5: Sensory scores of cookies prepared with tomato powder.

observed by other researchers, who reported that the spread ratio of cookies prepared with bamboo leaf powder decreased with increasing amount of bamboo leaves powder [10]. Cho et al. [11] also reported that the addition of sea tangle powder lowered the spread ratio of cookies. From these results, it is suggested that the incorporation of different ingredients into cookie products result in different physical properties. In general, cookie spread or diameter is used as an indicator of cookie quality and cookies with larger spread or diameter are considered more desirable [12].

\section{Color measurement}

The results of Hunter Lab color value of cookies are shown in Table 4. The L value (lightness) of control cookies was 52.33 and those of tomato powder cookies ranged from 50.35 to 47.45 , indicating that lightness decreased with the reduction in the proportion of wheat flour because of the loss of white color of the flour $(p<0.05)$. Therefore, it could be expected that cookies would become darker with increasing amount of tomato powder level. The 'a' value (redness) of control cookies was 3.31 and those of tomato powder groups were 5.68-8.56, showing more reddish color than control. This is attributable to the reddish color of tomato powder. The $b$ value (yellowness) of control group was 30.47 and cookies substituted with different levels of tomato powder ranged from 37.63 to 41.66 , having more yellowish color than control. Similar results were obtained by Kim et al. [9] who reported that the color of sugar- snap cookies became darker, more red and yellow with increasing amounts of barley germ. Singh et al. [13] reported that lightness value decreased while redness and yellowness values increased as the substitution.

\section{Sensory evaluation}

Results of sensory evaluation of cookies with added tomato powder are shown in Table 5. The color was evaluated to become darker as the tomato powder level increased, which is due to the reddish color of tomato powder. This is in agreement with the result of lightness values shown in Table 4 . Scores of tomato taste were higher in cookies added with tomato powder than those of control cookies because tomato powder gave a characteristic taste. The hardness score was higher in $5 \%$ substitution than those of cookies substituted with different levels of tomato powder. The appearance score was found higher in 5\% substitution level than rest of the treatments. Appearance score was judged on the basis of number of cracks on the surface of cookies. The higher the cracks with uniformity better will be the cookie. There were no significant differences in the overall desirability scores between control cookies and tomato powder added cookies. Therefore, replacing up to $5 \%$ wheat flour with tomato powder would not result in significant differences in the acceptability of cookies.

\section{Conclusion}

In the experiment it was concluded that the cookies incorporated with the tomato pomace powder were found acceptable up to $5 \%$ substitution. The color of the cookies becomes more and darker as the level of pomace powder increased. Spread factor of the cookies was increased due to the pomace incorporation.

\section{Acknowledgement}

This work was supported by the Post-Harvest Technology, Division of Shere-Kashmir University of Agricultural Sciences and Technology, Shalimar Srinagar. 
Citation: Bhat MA, Ahsan H (2015) Physico-Chemical Characteristics of Cookies Prepared with Tomato Pomace Powder. J Food Process Technol 7: 543. doi:10.4172/2157-7110.1000543

Page 4 of 4

\section{References}

1. Takachi R, Manami I, Junko I, Norie K, Motoki I, et al. (2008) Fruit and vegetable intake and risk of total cancer and cardiovascular disease: Japan public health center-based prospective study. American Journal of Epidemiology 167: 59-70.

2. Sancez MC, Valencia C, Ciruelos A, Latorre A, Gallegos C, et al. (2002) Rheological properties of tomato paste: Influence of the addition of tomato slurry. J Food Sci 68: 551-554.

3. Giovannucci E (1999) Tomatoes, tomato-based products, lycopene and cancer: Review of the epidemiologic literature. J Nat Cancer Inst 91: 317-331.

4. Rao AV, Agarwal S (1999) Role of lycopene as antioxidant carotenoid in the prevention of chronic diseases: a review. Nutr Research 19: 305-323.

5. Akanbi CTR, Adeyemi S, Ojo A (2006) Drying characteristics and sorption isotherm of tomato slices. Journal of Food Engineering 73: 157-163.

6. AACC (1995) Approved Methods of the AACC. American Association of Cereal Chemists, St Paul, MN
7. AOAC (1995) Official Methods of Analysis. Association of Official Analytical Chemists, Washington DC

8. Chung, KM, Kwon CS (1999) Properties of cookies added of flour and Chinese yam powder. Food Sci Biotechnol 8: 341-343.

9. Kim IS, Lee YT, Seog HM (2002) Effects of barley germ on sugar-snap cookie quality. Food Sci Biotechnol 11: 515-519.

10. Lee JY, Ju JC, Park H J, Heu ES, Choi SY, et al. (2006) Quality characteristics of cookies with bamboo leave powder. Korean J Food and Nutr 19: 1-7.

11. Cho HS, Park BH, Kim KH, Kim HA (2006) Antioxidative effect and quality characteristics of cookies made with sea tangle powder. Korean J Food Culture 21: $541-549$

12. Fimney KF, Morris VH, Yamazaki WT (1950) Micro versus macro cookie baking procedures for evaluating the cookie quality of wheat varieties. Cereal Chem 27: $42-49$.

13. Singh J, Singh N, Sharma TR, Saxena SK (2003) Physicochemical, rheological and cookie making properties of corn and potato flours. Food Chem 83: 387-393. 